\title{
CHARACTERIZATION OF ALLOY 718 MICROSTRUCTURES
}

\author{
Chantal PEYROUTOU and Yves HONNORAT \\ Materials and Processes Department \\ SNECMA \\ 91003 Evry-France
}

\begin{abstract}
Good understanding between suppliers and engine manufacturers is based upon the accuracy of microstructure description. In order to improve the accuracy of microstructural characterizations and particularly grain sizing, SNECMA is developing new procedures. These are proposed in this paper, after having discussed the current standard methods. The use of Image Analysis as grain sizing technique is of a great interest as it increases speed and accuracy and also provides individual morphological parameters which can be at the origin of standard documents improvement. Several examples of computerized classifications are presented.
\end{abstract}




\section{1 - Introduction}

As an engine manufacturer SNECMA widely uses A17oy 718 with a large set of microstructures, among which the selection is strongly dependant of the exact mode of stressing of the parts. It is well known that the exact combination of low cycle fatigue and creep stressing with temperature in a definite part is a function of its use and location in the hot gas stream. It is mandatory to evaluate accurately the life potential of each critical component, and the fact is that the versatility of the 718 microstructure offers the same use value for very different stressing combinations.

The long experience acquired at SNECMA on 718 critical components shows that it is possible to establish an accurate correlation between the life potential and the microstructure as far as a sensible enough grain size evaluation methodology can be used.

The averaging of distinctly different sizes may result in a non realistic description of the microstructures. On the basis of current ASTM-ISO standards, SNECMA is developing new methods of grain size microstructure evaluation enhanced by the use of Image Analysis.

\section{2 - Current standards and proposed improvements}

\section{1 - Single distribution of grain size}

Current standards ISO 643 and ASTM E112 (1-2) are applicable to respectively ferritic or austenitic steels and to fully recrystallized materials. Both are dedicated to equiaxed grains and define a $G$ index value independant of the units in which measurements are made. G can be obtained by estimating the number of grain sections per unit area, the number of grain intercept per unit length or by the value of the mean intercept distance.

Thus:

$G(I S O)=1$ for 16 grains per square millimeter, $G(A S T M)=1$ for 15.5 grains per square millimeter, $G(A S T M)=0$ for an average intercept length of $32.00 \mathrm{~mm}$ at $100 \times$ magnification

As a consequence, the ASTM size number is slightly higher than the ISO one:

$$
G(A S T M)-G(I S 0)=0.0458
$$

Grain size can also be expressed as dimensional parameters such as the diameter of the average grain, Feret's diameter or the average intercept distance. Three basic methods of determination of grain size are applicable. The most convenient is the direct comparison with charts. For higher accuracy, the planimetric or intercept procedures are recommended.

For non equiaxed structures, E112 and ISO 643 methods recommend making separate size determinations along the three principal directions of the specimen. Furthermore ISO 643 method characterizes the anisotropy of a grain by its elongation factor. 


\section{2 - Deviation from a single distribution}

In the case of hot worked matcrials, mixed grains are sometimes encountered and it becomes necessary to split the initial distribution into families of different grain sizes, each family being characterized by its area fraction.

Test methods for recognizing the presence of duplex grain size are provided in ASTM E1181 (3) standard document. They are applicable to completely or partially recrystallized materials containing several distributions with a significant $\Delta G$ of grain size numbers. The different grain families may be distributed in randomly or topologically varying patterns. The first category includes coarse individual grains distributed in a matrix of finer grains, extremely wide distribution of grain size and bimodal distributions. The second category deals with necklace or banding structures and germinative grain growth centres.

Finaly, each microstructure is classified according to the categories defined by the E1181 document. Table I illustrates some duplex conditions:

Table I Duplex conditions in E1181 methods

\begin{tabular}{|c|c|}
\hline CONDITIONS & DESCRIPTIVE REPORT \\
\hline $\begin{array}{l}\text { ALA (AS Large AS): } \\
G>3, \text { individual coarse } \\
\text { grain, randomly distributed } \\
\text { and covering } 5 \% \text { or less of } \\
\text { the area of the specimen }\end{array}$ & $\begin{array}{l}\text { Duplex, ALA, AGS ASTM } n^{\circ}-\text {, } \\
\text { OCC ALA ASTM } n^{\circ}- \\
\text { AGS: Average Grain Size } \\
\text { OCC: occasional }\end{array}$ \\
\hline $\begin{array}{l}\text { Wide range: } \\
\Delta G \geq 5, \text { wide range of grains } \\
\text { size randomly distributed }\end{array}$ & $\begin{array}{l}\text { Duplex, wide range, } \\
\text { AGS ASTM } n^{\circ}-- \text {, } \\
\text { range ASTM } n^{\circ}-\text { to ASTM } n^{\circ-}\end{array}$ \\
\hline $\begin{array}{l}\text { Bimodal: } \\
\Delta G \geq 4, \text { random } 7 \text { distributed } \\
\text { grain size, the two sizes } \\
\text { together cover } 75 \% \text { or more } \\
\text { of the total area }\end{array}$ & $\begin{array}{l}\text { Duplex, bimodal, } \\
--\% \text { AGS ASTM } n^{\circ}-- \\
--\% \text { AGS ASTM } n^{\circ}--\end{array}$ \\
\hline $\begin{array}{l}\text { Cross-section: } \\
\Delta G \geq 3 \text {, variation in grain } \\
\text { size along the section or } \\
\text { from one area to another }\end{array}$ & $\begin{array}{l}\text { Duplex, cross-section, } \\
\text { AGS ASTM } n^{\circ}-- \text { at centre to } \\
\text { AGS ASTM } n^{\circ}-- \text { at surface }\end{array}$ \\
\hline $\begin{array}{l}\text { Neck } 1 \text { ace: } \\
\Delta G \geq 3 \text {, individual coarse } \\
\text { grains surrounded by finer } \\
\text { grains }\end{array}$ & $\begin{array}{l}\text { Duplex, necklace, } \\
--\% \text { AGS ASTM } n^{\circ}-- \\
--\% \text { AGS ASTM } n^{\circ}--\end{array}$ \\
\hline$\frac{\text { Banding: }}{\Delta G \geq 3}$ & $\begin{array}{l}\text { Duplex, banding, } \\
--\% \text { AGS ASTM } n^{\circ}-- \text {, } \\
--\% \text { AGS ASTM } n^{\circ}--\end{array}$ \\
\hline
\end{tabular}




\section{3 - Proposed improvements}

In the same way as E112 methods, SNECMA is developing new procedures to precisely quantify grain structures. The basic principles (cxamined areas, statistical consideration...) are similar but the classification proposed in this paper provides for a larger set of duplex conditions and improves the accuracy of the final report. We present here the broad outline of the improved procedure.

\section{Grain size measurement units}

In most of the cases, grain size is characterized by a $G$ index such as $G=1$ for 16 grains per square millimeter. In specific cases, grains are described by their real dimension in millimeters (see scattered grains).

\section{Shape factor}

Let us consider the length $L$ and the width 1 of a grain on a cross section. The shape factor $F$ is defined by the ratio $L / 1$.

Conventionnally, a grain is equiaxed as long as $F \leq 2$. 0therwise, the grain belongs to the non-equiaxed category.

\section{Class definition}

According to the difference $\Delta G$ of grain size numbers, we define three classes:

class 1: $\Delta G<2$, single population structure

class 2: $2 \leq \Delta G<4$, mixed grain sizes

class 3: $\Delta G \geq 4$, duplex grain sizes

\section{Type of distributions}

Each population of grain is refered to a symbol with respect to its area fraction and distribution as indicated in Table II. 
Table II Conditions for each type of distribution

\begin{tabular}{|l|c|c|}
\hline \multicolumn{1}{|c|}{ CONDITIONS } & $\begin{array}{c}\text { TYPE OF } \\
\text { DISTRIBUTION }\end{array}$ & SYMBOL \\
\hline $\begin{array}{l}\text { Single population or several } \\
\text { populations interpenetrating } \\
\text { themselves continuously without } \\
\text { important agglomeration or local } \\
\text { disappearance of one population }\end{array}$ & uniform & U \\
\hline $\begin{array}{l}\text { Populations distributed in nearly } \\
\text { parallel bands }\end{array}$ & alternated & A \\
\hline $\begin{array}{l}\text { Two populations in which smaller } \\
\text { grains are surrounding larger ones } \\
\text { (area fraction of smal1 grain is } \\
\text { between 5 and 60\%) }\end{array}$ & necklace & C \\
\hline $\begin{array}{l}\text { One of the population is homogeneous7y } \\
\text { distributed into clusters containing } \\
4 \text { grains or more }\end{array}$ & clustered & I \\
\hline $\begin{array}{l}\text { One of the population consists of } \\
\text { linear clusters (4 grains or more) } \\
\text { due to the dendritic solidification }\end{array}$ & dendritic & D \\
\hline
\end{tabular}

\section{Grain aspect}

Grain aspect is refered to a symbol as shown in table III.

Table III Grain aspect

\begin{tabular}{|l|c|c|c|}
\cline { 2 - 4 } \multicolumn{1}{c|}{} & \multicolumn{3}{c|}{ RECRYSTALLIZATION } \\
\hline GRAIN MORPHOLOGY & NONE & PARTIAL & TOTAL \\
\hline EQUIAXED & E & T & S \\
\hline NON-EQUIAXED & N & $P$ & $M$ \\
\hline
\end{tabular}

\section{Scattered grains}

If coarse grains represent less than $25 \%$ of the observed area, show a size greater than a given value related to the surrounding population (e.g $\geq 0.18 \mathrm{~mm}$ for $G=6$ ) and are adjoining by at most 3 , they do not form a population but are called scattered grains. The distribution of these grains can be uniform, alternated, clustered or denditric. They are characterized by the dimension in millimeters of one of the coarser grains: the length $L$ for equiaxed grains, the ratio $(L+1) / 2$ for non-equiaxed grains. This dimension is preceded by the symbol "qq". 


\section{Final report}

The examined area must be described by:

- the class of the structure (type 1,2 or 3 ),

- the population distribution (U, A, C, I or D),

- the principal population (defined by the highest area fraction) characterized by its area fraction, its $G$ index and its aspect,

- the secondary population characterized by its $G$ index and its aspect,

- the scattered grains characterized by their distribution, their dimension $(\mathrm{mm})$ and their aspect.

Example of quotation:

A structure codified $2 \mathrm{C60} \%$ 8.5E5Tqqu0.25mm consists of a mixed structure (class 2) with a necklace repartition (C). The majority population with a $G$ index of 8.5 represents $60 \%$ of the area. Grains have an equiaxed aspect with no recrystallization $(E)$. The minority population $(G=5)$ is made of equiaxed grains showing a partial recrystallization $(T)$. Scattered grains of $0.25 \mathrm{~mm}$ (qq) al so exist. They are equiaxed and partially recrystallized (T).

\section{3 - Characterization of grain size distribution by Image Analysis}

\section{1 - Justification}

The use of computerized Image Analysis is of a great interest in metallurgy as it enhances the performance of traditionnal measurements. Speed and accuracy are increased. The computer capability to process a bigger amount of data improves grain sizing reliability (4-5). Moreover, new information like individual morphological parameters, among others, provided by computerized techniques can lead to a better understanding of metallurgical phenomena (6) but also can be at the origin of the improvement of existing standard documents. This subject forms the object of the second part of this paper.

\section{2 - Computerized parameters}

A classical microstructural analysis device connected to a light microscope and providing numerical images with a $512 \times 512$ pixels definition on 256 gray levels was used to perform morphological measurements.

The first difficulty when computerizing grain size is to properly digitalize the microstructure. Although the sample is prepared with stringent precautions: polishing, etching and the image quality is improved by the means of preprocessing operations, the presence of twinned grains or incomplete grain boundaries doesn't allow a correct digitalization. As a consequence, these imperfections must be manually corrected in the numerical image. Note that several attempts have been made to automatically close grain boundaries and recognize twinned grains (7). 
Basically, according to standard methods, grain sizing is a global measurement and grains are seldom individually measured. classical line intercept method gives a good overview of grain populations existing in a duplex structure. As a matter of fact, the presence of grains having a significant $\Delta G$ of grain size numbers appears in the form of a bimodal histogram of intercepted lengths (see ASTM E1181 methods). But when the complexity of the microstructure increases (non-equiaxed grains, scattered grains) the grain disposition may become inextricable. It is also important to notice that human vision which is particularly sensitive to irregularities may sometimes lead to an erroneous interpretation of microstructures.

Image processings give the opportunity not only to implement routines applying procedures as defined in standard methods but also to collect individual data. Thus, two different types of measurements have been carried out:

- global measurements: with respect to standard methods, the $G$ index can be determined by measuring the average surface of the grains $m$ (e.g. the global surface of the area divided by the total number of grains), then applying the ISO formula: $m=8 \times 2^{G}$,

- individual measurements: for each grain completely included in the field, six individual parameters are determined, as shown in table IV.

Table IV computerized individual parameters

\begin{tabular}{|c|l|}
\hline PARAMETER & \multicolumn{1}{|c|}{ SIGNIFICATION } \\
\hline Sx & Surface of a grain \\
\hline$D D$ & $\begin{array}{l}\text { Maximum Feret's diameter } \\
\text { (almost equal to the length } L)\end{array}$ \\
\hline$D L$ & $\begin{array}{l}\text { Minimum Feret's diameter } \\
\text { (almost equal to the width } 1)\end{array}$ \\
\hline$(D D+D L) / 2$ & $\begin{array}{l}\text { Caracteristic dimension for } \\
\text { scattered grains }\end{array}$ \\
\hline$F=D D / D L$ & Shape factor \\
\hline$G=(\log (1 / S x) / \log 2)-3$ & Individual grain size number \\
\hline
\end{tabular}


It must be noticed that an individual grain size number $G$ is evaluated by this procedure. This, of course, seems to be an heresy compared to the original standard definition of grain size number. Moreover, the average grain size number determined by averaging the different individual $G$ index cannot be compared with the $G$ index calculated according to standard methods (presence of a logarithm). They typically differ from 0.5 to 1 in the case of a single population of grains, and up to 3 or 4 in the case of multimodal distributions. But as it will be shown hereafter, the individual $G$ index which is a normalized parameter is of a great interest when comparing microstructures.

\section{3 - General image processing}

The choice of the magnification is such that the smallest grains are represented by a sufficient number of pixels. Actually, a compromise must be found between the size of the smallest grain and the number of grains contained in a field. This parameter can be adjusted by multiplying the number of fields. Afterwards, the magnification value is taken into account by the pixel size.

In order to enhance grains boundaries, a Laplacian filter is first applied. In the corresponding binary image, grain boundaries are replaced by their squeleton. As a matter of fact, the bounderies width generate an error on individual surface evaluation and the global surface of the boundaries may represent $10 \%$ of the total area. By reducing the bounderies width to the pixel size, this proportion can be reduced up to a few percentage points.

\section{4 - ASTM standard charts}

$G=6.5$ and $G=8$ ASTM standard charts have been computerized and characteristic distributions of individual surfaces and individual $G$ index were determined as shown in figure 1 .

The general shape of the distributions is similar especially for the individual $G$ index on which, moreover, differ in height and in the position of the maximum: for example a 1.5 shift from ASTM $n^{\circ} 6.5$ to ASTM $n^{\circ} 8$. The position of the maximum is directly connected to the size of the grains in each microstructure. The variation of the height of the peaks cannot be compared from one chart to another as the total number of grains widely varies (chart ASTM $n^{\circ} 6.5: 114$ grains, chart ASTM $n^{\circ} 8: 1405$ grains). Thus by shifting the ASTM $n^{\circ} 8 \mathrm{G}$ histogram, it is possible to simulate any other ASTM standard distribution. This is particularly interesting when the corresponding chart is not available. 


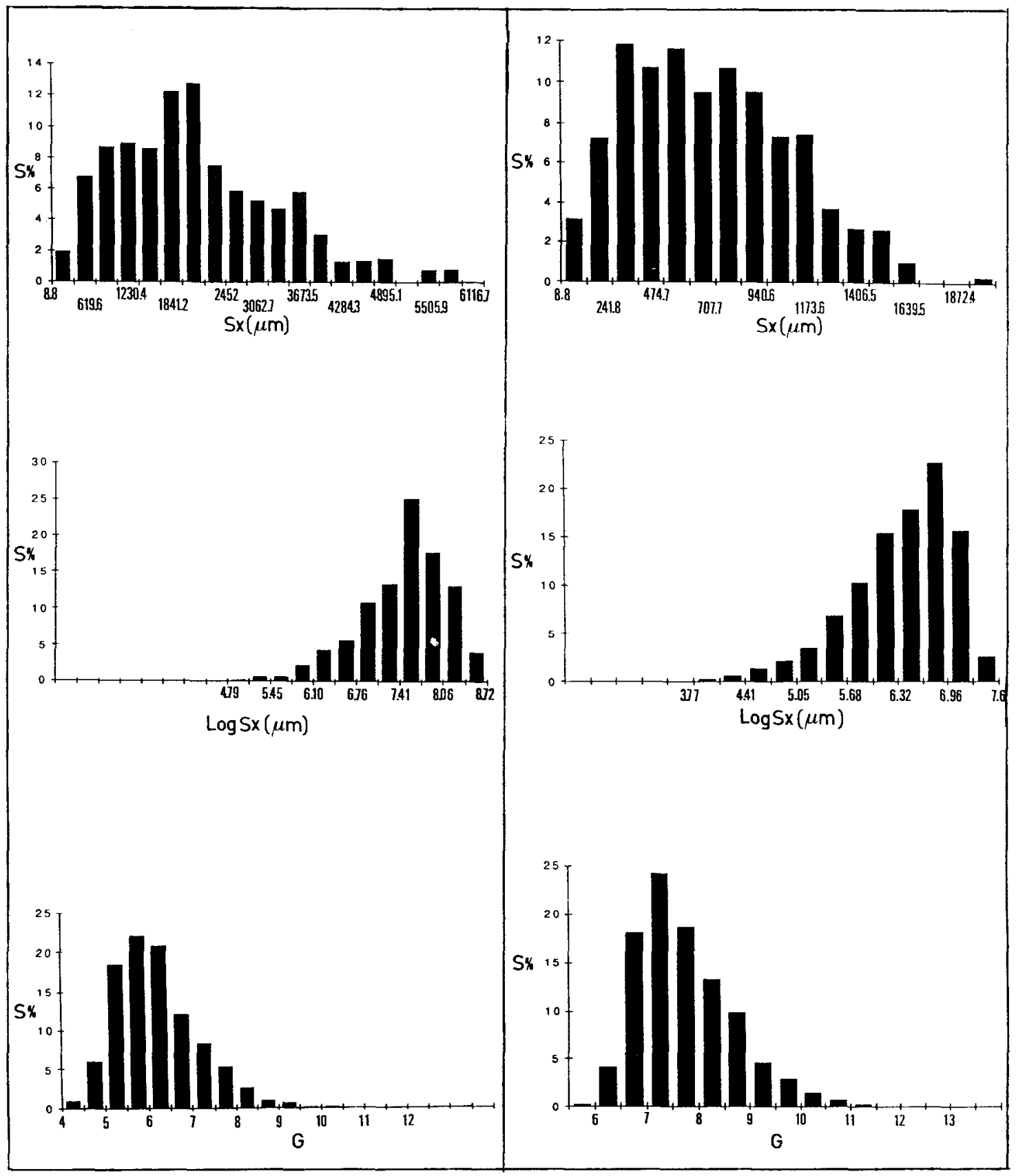

(a)

(b)

Figure 1 - Individual $G$ index and surface distributions in standard charts (a) ASTM $n^{\circ} 6.5$, (b) ASTM $n^{\circ} 8$ 


\section{5 - Examples}

\subsection{1 - Example 1: ASTM duplex distribution chart}

This first example illustrates the efficiency of the new methods proposed by SNECMA. The microstructure which has been computerized is extracted from the ASTM E1181 standard methods (see figure 2). It is given in this document as being a duplex, wide range structure of average grain size ASTM $n^{\circ} 4$, range ASTM $n^{\circ} 0$ to $\operatorname{ASTM} n^{\circ} 7$.

The first step when computerizing grain size is to determine if scattered grains exist in the microstructure. This is quite easy to perform as scattered grains have a little influence on the average grain size number (at most a difference of 0.5 in $\Delta G$ ). The algorithm to perform is the following:

a) determine the average size number $G$ of the global microstructure by the standard method ( $G=4.30$ for 425 grains),

b) look for the dimension $d$ of scattered grains related to the average size number $(d=0.27 \mathrm{~mm})$,

c) split the initial image into equiaxed grains $(F \leq 2)$ and non-equiaxed grains,

d) select the equiaxed grains verifying $D D>d$,

e) select the non-equiaxed grains verifying $(D D+D L) / 2>d$,

f) perform a logical union between the two preceding images,

g) test the area fraction of the selected grains.

The effects of this algorithm are illustrated on figure 2. There are few grains of non-equiaxed morphology $(3.7 \%$ of total area), none of them verifies $(D D+D L) / 2>d$. Among the equiaxed grains, three correspond to a length superior to $d$. The area fraction of these grains represents $9.4 \%$ of the total area. Therefore, they belong to the scattered grains category.

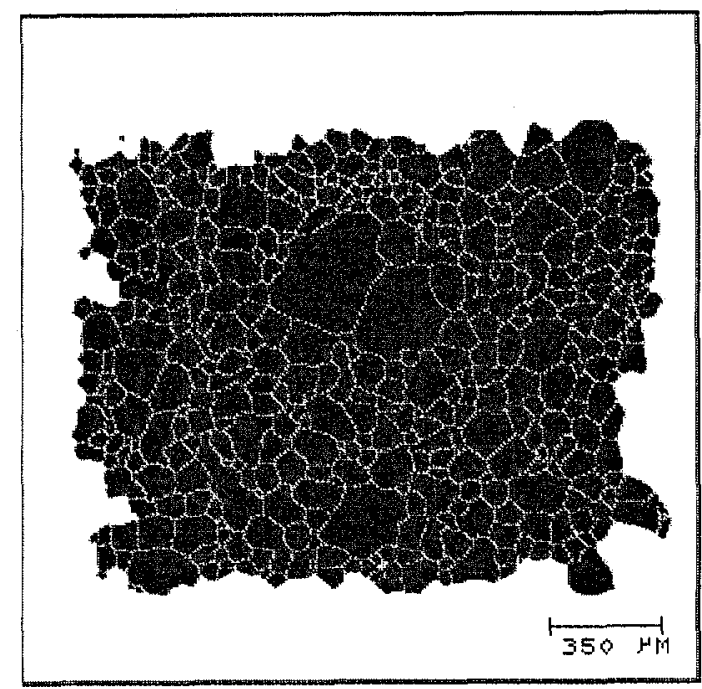

(a)

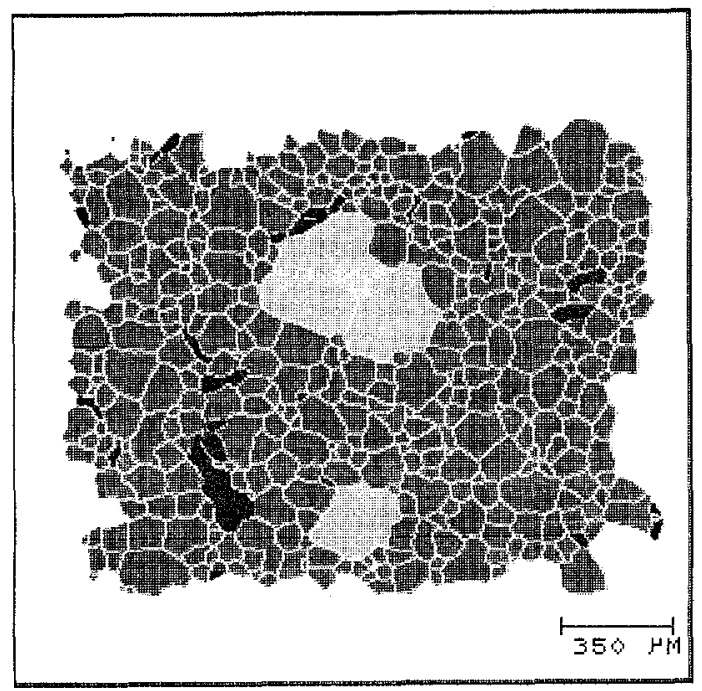

(b)

Figure 2 - Revealing scattered grains
a) initial field

b) lightest grains: equiaxed, DD $>d$ darkest grains: non-equiaxed morphology 
Their distribution can be evaluated by mathematical morphology. After having isolated the scattered grains by performing a morphological closing in order to connect the adjoining grains (figure 3 ), it is possible to determine if clusters exist. In this case, the distribution is uniform, two binary objects still remain after the closing operation. Scattered grains will be characterized by the dimension of the coarser grain: $D D=0.46 \mathrm{~mm}$.

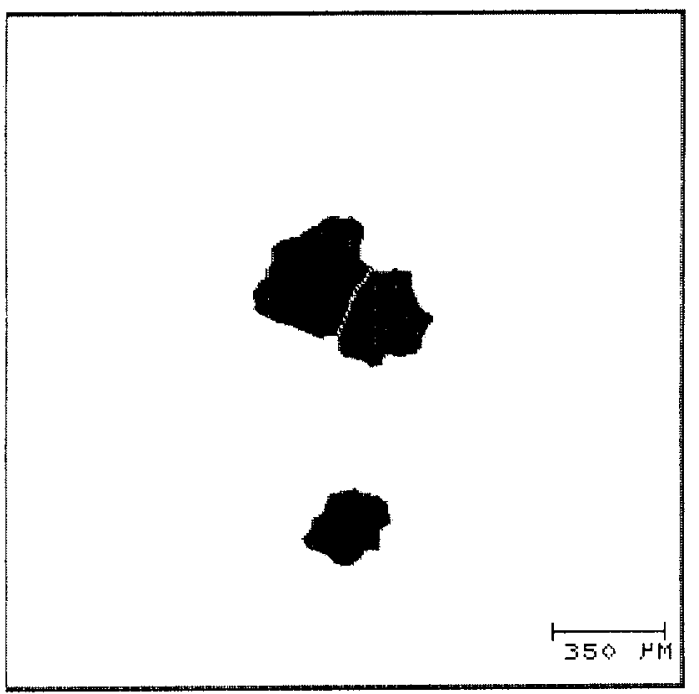

(a)

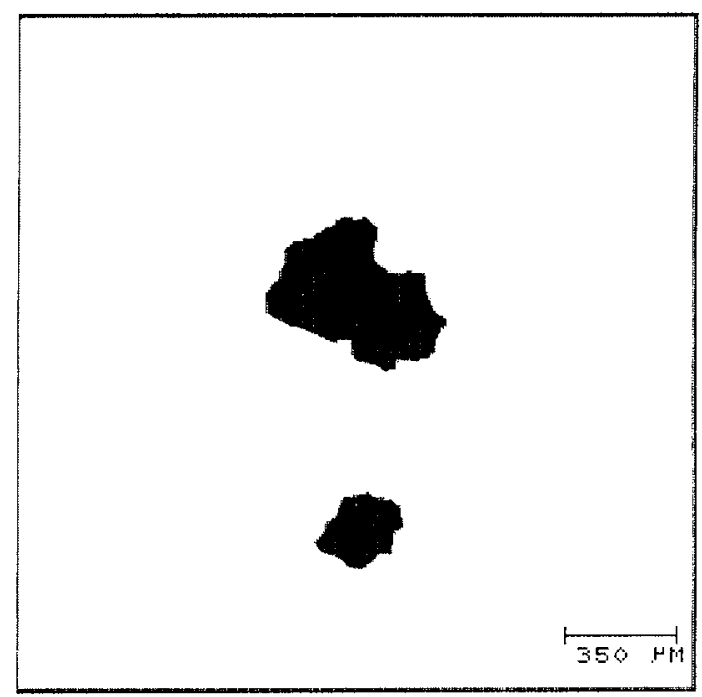

(b)

Figure 3 - Type of distribution.
a) before closing operation
b) after closing operation

The second step is now to quantify the remaining structure e.g. to determine the average grain size number with respect to the standard method and the individual parameters as described in $\S 3.2$. The thus calculated $G$ index is 4.6, figure 4 shows its distribution.

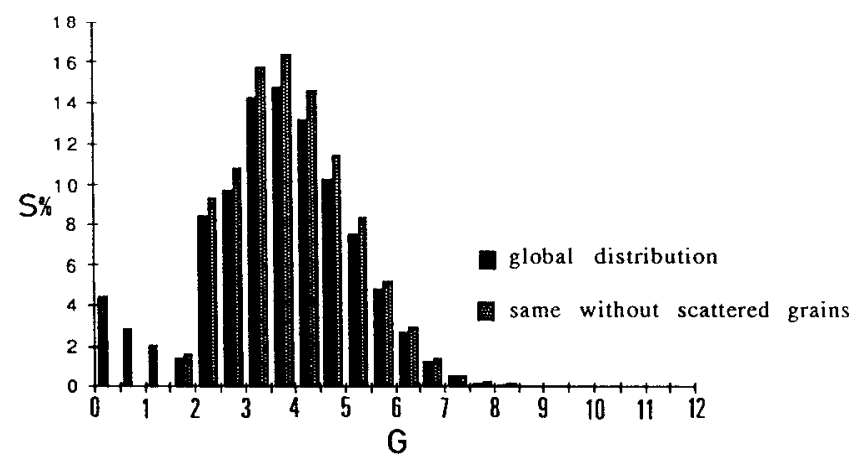

Figure 4 Histogram of $G$ index 
The comparison of the histogram of $G$ index with the reference ASTM $n^{\circ} 4.5$ one shows a good agreement between the two distributions (figure 5 ). Thus, the remaining grains form a single population with an average $G$ index of 4.5 . Finally, this microstructure belongs to a uniform class 1 distribution (90.6\%) having an average size number of 4.5 and associated to scattered grains of $0.46 \mathrm{~mm}$ : 1 U90.6\% $4.5 \mathrm{Eqqu} 0.46 \mathrm{~mm}$.

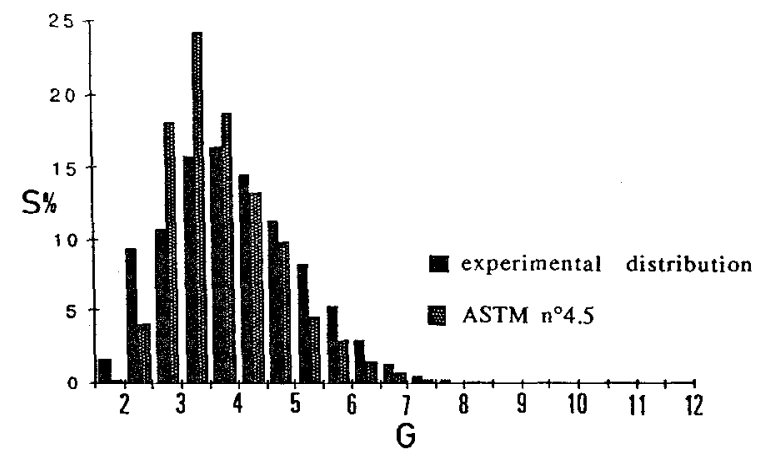

Figure 5 - Comparison of $G$ index histograms

Note that the average size number determined with this procedure is slightly different from the ASTM quotation (0.5).

\subsection{2 - Example 2: uniform population of grains}

The microstructure shown in figure 6 a has been evaluated with this algorithm described above. Neither scattered grains nor non-equiaxed grains have been detected among 279. The $G$ index histogram correctly superposes on the reference ASTM $n^{\circ} 8.5$ one (figure $6 \mathrm{c}$ ). Therefore, this microstructure is classified as a class 1 , uniform distribution.

\subsection{3 - Example 3: duplex, necklace distribution}

In the presence of a necklace pattern of variation (figure $7 a$ ), it is necessary to introduce another algorithm in order to split the two grain families. We have used a separation threshold based upon the comparison of the area fraction and the number of grains fraction.

Let us consider two populations of grains such as the first population counts $n 1$ grains with a surface distribution $\left(S_{1 j}\right)$ for $i=1$ to $n 1$ and the second population counts $n 2$ grains with a surface distribution $\left(S_{2 j}\right)$ for $i=1$ to $n 2$. The respective area fractions and number of grains fractions are given by:

$$
\begin{array}{cc}
n 1 \%=n 1 /(n 1+n 2) & n 2 \%=n 2 /(n 1+n 2) \\
S 1 \%=\Sigma S_{1 i} /\left(\Sigma S_{1 i}+\Sigma S_{2 i}\right) & S 2 \%=\Sigma S_{2 i} /\left(\Sigma S_{1 i}+\Sigma S_{2 i}\right)
\end{array}
$$

The average grain surface for each population can be written:

$\overline{S 1}=\Sigma S_{1 i} / n 1$

$\overline{S 2}=\Sigma S_{2 i} / n 2$ 
(a)

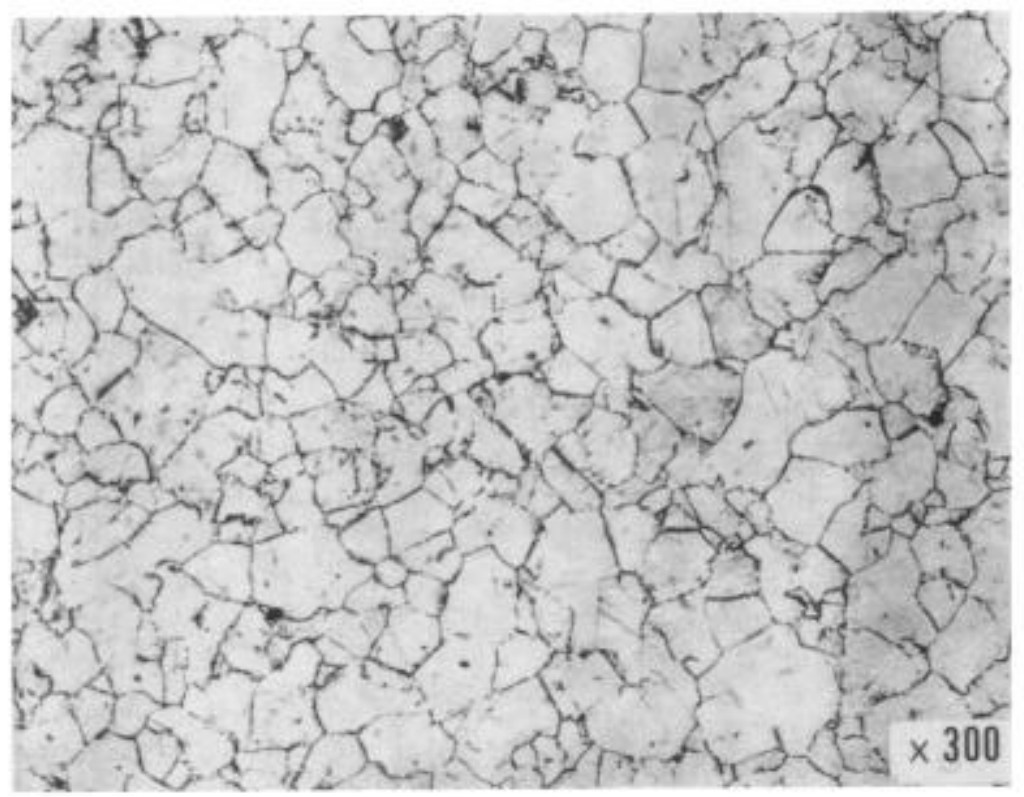

(b)

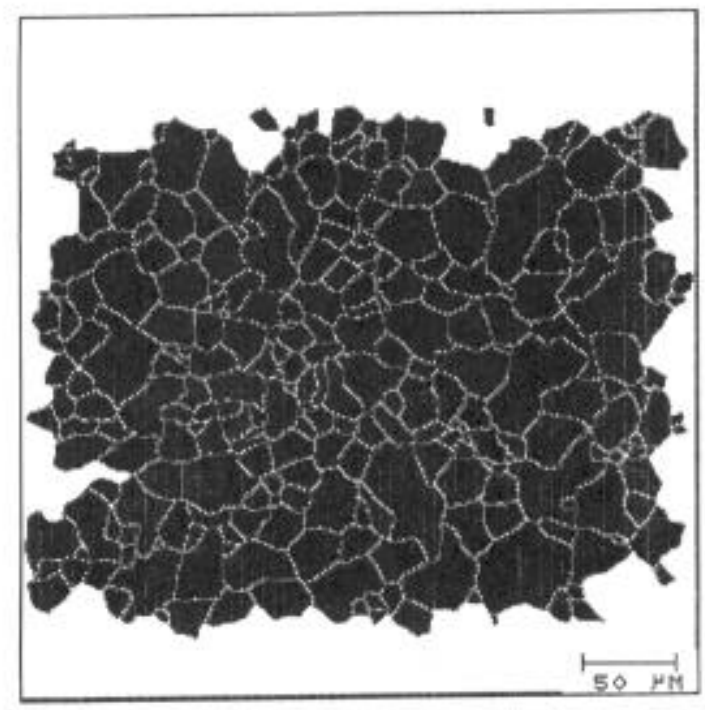

(c)

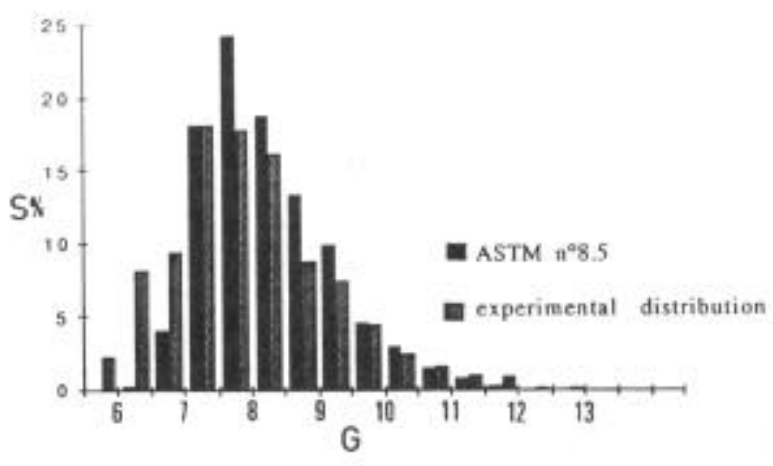

Figure 6 - Example of a uniform population of grains:

(a) light micrography - (b) digitalized image - (c) comparison with ASTM 
Which it can be shown becomes:

$S 1 \%=\overline{S 1} n 1 /(\overline{S 1} n 1+S 2 n 2)$ and $S 2 \%=\overline{S 2} n 2 /(\overline{S 1} n 1+\overline{S 2} n 2)$

In any case, $\overline{S 1}>\overline{S 2}$ or $\overline{S 2}>\overline{S 1}$, the general relations $n \%>S \%$ for the smallest grains and $n \%<5 \%$ for the coarser grains are verified. The algorithm compares the distributions and the separation threshold is defined by the first value of $\mathrm{Sx}$ for which $5 \%>n \%$. Figure $7 \mathrm{~b}$ shows the thus isolated populations of grains.

(a)

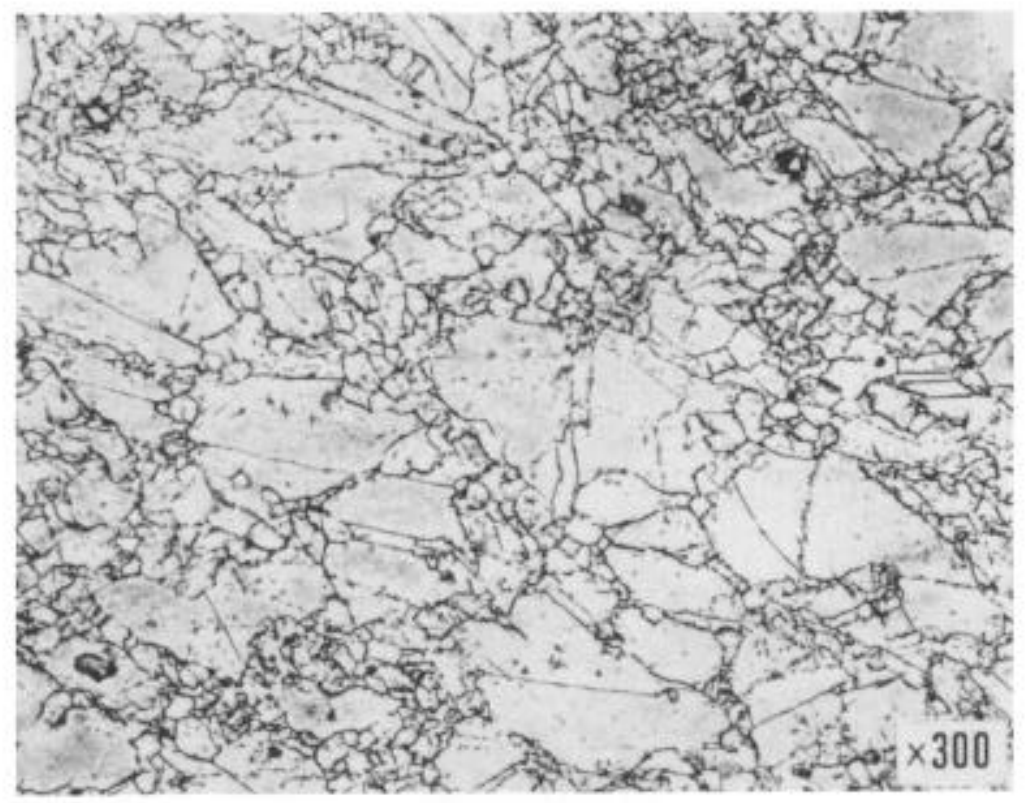

(b)

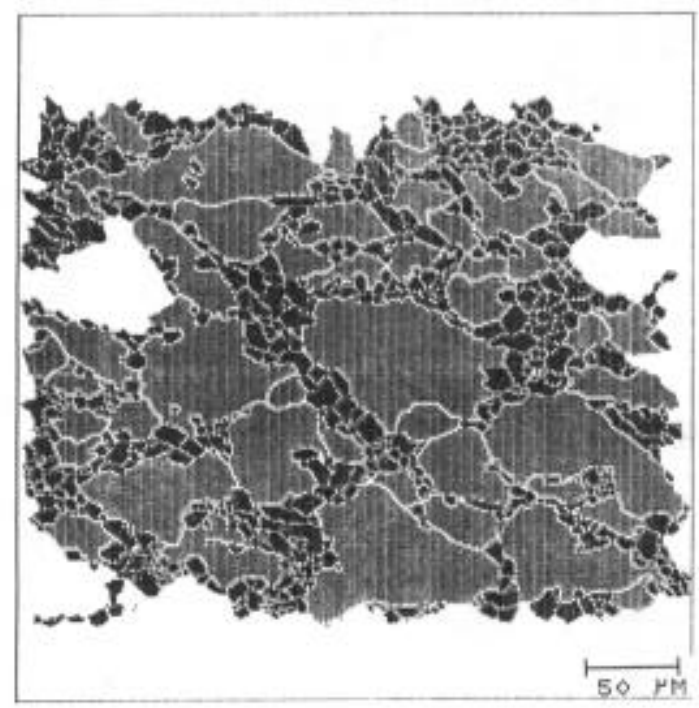

Figure 7 - Necklace populations:

(a) light micrography

(b) effect of the separation threshold 
Thus, the characteristic of these two populations are:

- population 1 (coarse grains): $G=7$ (6.88 measured), $S \%=64$

- population 2 (smal1 grains): $G=11.5$ (11.68 measured), $S \%=36$

\subsection{4 - Example 4: duplex, uniform distribution}

This example differs from the preceding one because the area fraction occupied by the smallest grains is higher than $60 \%$ (see figure 8 ).

- population 1: $G=9$ (9.09 measured), $S \%=71.1$

- population 2: $G=4$ ( 3.98 measured), $S \%=28.3$

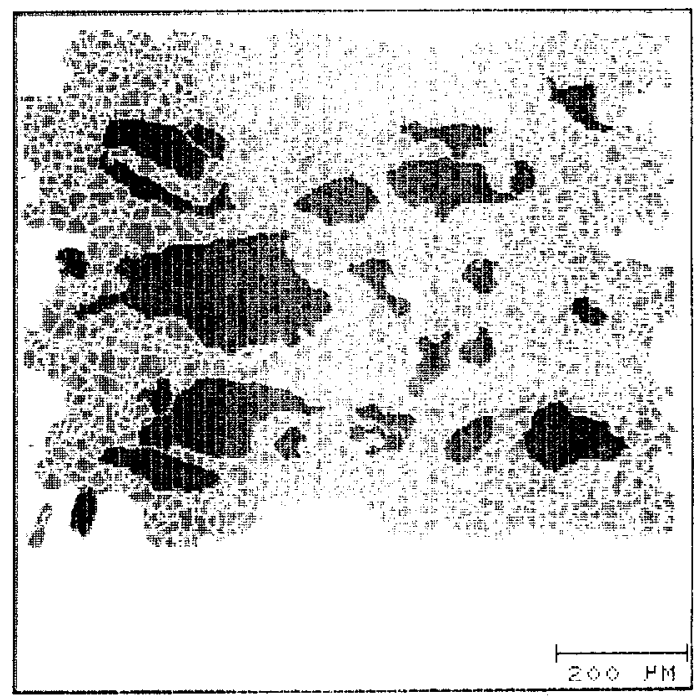

Figure 8 - Duplex distribution

$$
4 \text { - Conclusion }
$$

In order to improve the accuracy of 718 forged component grain sizing, a new procedure for the classification of the microstructures has been developed in the SNECMA Material Laboratory. Image Analysis as a classification technique provides appreciable results especially when the microstructural scheme is complex.

The use of an individual $G$ index related to each grain is a particularly interesting approach when characterizing a grain microstructure. By computerizing standard charts, it is possible to obtain a set of reference distributions which can be compared with other experimental ones. Reference distributions are also convenient to simulate any other distribution when the corresponding chart is not available. 
The problem of isolating populations with a significant $\Delta G$ of grain size numbers can be solved by comparing the surface fraction $5 \%$ with the corresponding number percentage $n \%$. When the $\Delta G$ difference decreases, it is preferable to proceed by comparison with the reference distributions. As a matter of fact, the $5 \%$ against $n \%$ criterion will always provide a separation threshold: in the case of standard chart distributions, two populations covering respectively 70 and $30 \%$ of the total area are thus artificially splitted.

Topologically varying patterns can be automatically performed by means of mathematical morphology transformations such as closing. It is thus possible to test if grains are adjoining or not or if small grains surround coarser ones.

Finally, this procedure is well adapted to laboratory investigations but is still too sophisticated to be an usual control mean. For the near future, our goal is to evolve the technique into an easily usable control menu.

\section{REFERENCES}

\section{International Organization for Standardization}

Steels - Micrographic determination of the ferritic or austenitic grain size. Ref $n^{\circ}$ : ISO 648-1983 (F).

\section{American Society for Testing and Materials,}

Standard Methods for Determining Average Grain Size, ASTM Designation: E112-84 (Philadelphia, PA, 30 march, 1984).

\section{American Society for Testing and Materials}

Standard Test Methods for Characterizing Duplex Grain Size ASTM Designation: E1181-87.

4. J.I. SIEGEL, N. KARASIKOV and Y. KYDAR, "Automated Image Analysis in Metallurgy", Quality, (march 1982), 58-60.

5. C.J. TWEED, N. HANSEN, B. RALPH, "Methods of Assessing Grain Size Distribution During Grain Growth, " Metallography, 18 (1985), 115-127.

6. H.E. EXNER, "Analysis of Grain - and Particle - Size Distributions in Metallic Materials," International Metallurgical Reviews, 17 (1972), 25-50.

7. M.B. KURDY, "Transformations Morphologiques Directionnelles et Adaptatives: Applications aux Sciences des Matériaux," (thesis, ENSM Paris, 1990). 